\title{
PELATIHAN TEKNIS SUPERVISI KLINIS BAGI PENGAWAS DAN KEPALA SEKOLAH DI KECAMATAN DIMEMBE
}

\author{
Jetty Fientje Kaunang \\ Fakultas Ilmu Pendidikan, Universitas Negeri Manado \\ jettyfkaunang@gmail.com
}

\begin{abstract}
Abstrak
This training aims to increase knowledge and skills in supervision using the clinical supervising technique for supeintendents and head masters. This training is very useful especially for the duty as supervisors for teachers that are in need of guidance. Stages in training clinical supervision training are informing and the training it self. According to the stages that have been done, it is concluded that the conduction of clinical supervision technique is very helpful for superintendents and head masters in their duty to help, guide the teachers in correcting and adding value to studying and teaching process in schools.

Kata Kunci: Clinical supervising, training, supeintendents, head masters
\end{abstract}

\section{PENDAHULUAN}

\section{Analisis Situasi}

UU. No.22 tahun 1999 tentang otonomi daerah memberikan kewenangan kepada daerah untuk mengatur dan mengurus kepentingan measyarakat sendiri. Kewenangan daerah mencakup semua bidang pemerintahan di antaranya bidang pendidikan dan kebudayaan. Pengembangan penddikan sangat bergantung atas kebijakan pemerintah daerah sebagai bagian dari kewenangan yang dilimpahkan. Melalui otonomi pengelolaan pendidikan diharapkan pemenuhan kebutuhan masyarakat lebih cepat tepat efisien dan efektif. Seiiring dengan perkembangan ilmu pengetahuan, teknologi dan seni yang berlangsung begitu pesat tidak dapat lagi diikuti dengan kasat mata sehingga menimbulkan berbagai permasalahan yang sangat rumit dan kompleks serta memerlukan pemecahan secara profesional. Dalam bidang pendidikan diperlukan berbagai teknologi dan inovasi untuk memecahkan berbagai permasalahn yang menyngkut proses belajar mengajar baik yang berkaitan dengan kebijaksanaan, manajemen, pendekatan strategi, isi maupun sumbersumber pendidikan dan pembelajaran. Untuk kepentingan tersebut para personil pendidikan di antaranya guru, harus senantiasa meningkatkan pengetahuan dan ketrampilannya agar dapat mengelola proses belajar mengajar secara efektif dan efisien. Pada dasarnya guru memiliki potensi yang cukup tinggi untuk berkreasi dan meningkatkan kinerja, namun banyak factor yang menghambat mereka dalam mengembangkan berbagai potensinya secara optimal. Oleh karena itu sangat dirasakan perlunya pembinaan yang continue dan berkesinambungan dengan program yang terarah dan sisitematis terhadap para guru dan personil pendidikan lain di sekolah. Tanggung jawab pembinaan 
dan pengembangan professional guru SD berada di tangan pimpinan dalam hal ini pengawas maupun kepala sekolah. Sebagai tenaga Pembina pendidika tentu harus menguasai atau memiliki suatu teknik atau strategi supervisi yaitu teknik supervisi klinis. Teknik supervisi klinis adalah salah satu strategi untuk membantu guru atau calan guru memperbaiki dirinya dalam hubungan dengan kegiatan pembelajaran.

Kegiatan pengabdian pada masyarakat yang dilaksanakan ini berkaitan dengan upaya memberikan pemahaman dan ketrampilan bagi para pengawas dan kepala sekolah tentang salah satu teknik supervisi yang dikenal dengan supervisi klinis.

Masalah yang dihadapi adalah mengungkapkan apakah masih terdapat kesenjangan antara apa yag diharapkan dengan kenyataan berkaitan dengan pemahaman, pengetahuan, dan keterampilan para pengawas dan kepala sekolah berkaitan dengan teknik supervisi klinis di wilayah kecamatan Amurang kabupaten Minahasa Selatan. Kenyataannya sebagian pengawas dan kepala sekolah belum menerapkan teknik supervisi klinis. Sehingga diperlukan pelatihan Teknik Supervisi Klinis kepada para pengawas dan kepala sekolah.

\section{Tujuan dan Manfaat}

Tujuan dari kegiatan ini yaitu:

1. Menambah pengetahuan dan keterampilan dalam hal pengawasan khususnya teknik supervisi klinis kepada para pengawas dan kepala sekolah.

2. Member pelatihan keterampilan teknik supervisi klinis bagi para pengawas dan kapala sekolah dasar di wiliayah kecamatan Amurang kabupaten Minahasa Selatan.

Adapun manfaatnya sebagai berikut:

1. Bagi Para pengawas, pelatihan ini bermanfaat sebagai pegangan mereka dalam melaksanakan tugas pembinan baik bagi para kepala sekolah maupun guru dibawah tanggung jawab pembinaannya.

2. Bagi kepala sekolah pelatihan ini bermanfaat terutama dalam melaksanakan tugas mereka sebagai supervisor bagi guru-guru yang berada di bawah tanggung jawab pembinaannya.

\section{Kerangka Pemecahan Masalah}

Teknik supervisi klinis adalah teknik pengawasan yang sangat membantu para guru dalam memperbaiki dan meningktkan proses belajar mengajar. Pada prakteknya pelaksanaan pengawasan di sekolahsekolah khususnya di sekolah dasar pelaksanaannya masih terkesan sebagai Inspeksi dalam arti mencari-cari kesalahan dan bukan membantu atau membimbing. Bahkan teknik supervisi klinis ini dapat dikatakan masih merupakan hal baru bagi kepala sekolah. Oleh sebab itu untuk membekali dan menambah pengetahuan serta keterampilah bagi petugas kepengawasan, maka perlu dilaksanakan 
pelatihan teknik supervisi klinis, prinsipprinsip supervisi klinis, cirri-ciri supervisi klinis, tujuan supervisi serta prosedur pelaksanaan supervisi klinis.

Danim (2011) mengatakan supervisi klinis adalah bantuan professional kesejawatan oleh supervisor kepada guru yang mengalami masalah dalam pembelajaran agar yang bersangkutan dapat mengatasi masalahnya dengan menempuh langkah yang sistematis, dimulai dari tahap perencanaan, pengamatan prilaku guru mengajar, analisis prilaku, dan tindak lanjut. Supervisi klinis juga merupakan proses bantuan atau terapi professional yang berfokus pada upaya perbaikan pembelajaran melalui proses siklikal yang sistematis dimulai dari perencanaan, pengamatan perilaku guru mengajar, analisis yang intensif terhadap penampilan guru dengan tujuan untuk memperbaiki proses pembelajaran.

Depdikbud (1985) supervisi klinis adalah suatu bentuk bantun yang diberikan kepada guru/calon guru berdasarkan kebutuhannya melalui siklus sistematik dalam perencanaan, pengamatan yang cermat, dan pemberian balikan segera dan obyektif tentang penampulan mengajarnya yang nyata. Untuk meningkatkan ketrampilan mengajar dan sikap profesionalnya. Bolla J.J. (1983): supervisi klinis adalah suatu proses bimbingan yang bertujuan membantu pengembangan profesi guru/ calon guru, khusus di penampilan mengajar berdasarkan observasi dan analisis data secara teliti dan obyektif sebgai pegangan untuk perubahan tingkah laku mengajar tersebut.

Supervisi klinis dapat diartikan sebagai bentuk bimbingan profesional yang diberikan kepada guru berdasarkan kebutuhannnya melalui siklus yang sistematis. Siklus sistematis ini meliputi: perencanaan, observasi yang cermat atas pelaksanaan dan pengkajian hasil observasi dengan segera dan obyektif tentang penampilan. Luh Ahmani dkk (2013) mengajarnya yang nyata.

Menurut Danim(2011) prinsipprinsip supervisi klinis yang harus diketahui oleh seorang supervisor:

1. Hubungan supervisor dengan guru disadari semangat kolegialitas yang taat asas;

2. Setiap kelemahan atau kesalahan guru semata-mata digunakan untuk tindakan perbaikan tanpa secara eksplisist melihat guru belum professional;

3. Menumbuhkembangkan posisi guru, mulai dari tidak professional sampai professional sungguhan;

4. Hubungan antara supervisor dengan guru dilakukan secara obyektif, transparan dan akuntabel;

5. Diskusi atau pengkajian atas umpan balik yang segera atau yang diketahui kemudian bersifat demokratis dan didasarkan pada data hasil pengamatan;

6. Hubungan antara supervisor dengan guru bersifat interaktif, terbuka, obyektif, dan tidak bersifat menyalahkan; 
7. Pelaksanaan keputusan atau tindakan perbaikan ditetapkan atas kesepakatan atau kerelaan bersama;

8. Sopervisor tidak mempublikasikan kelemahan-kelemahan guru dan guru tidak menjadikan kelemahan supervisor sebagai dalih untuk tidak menerima bimbingan professional darinya;

9. Focus utama dan pelengkap kegiatan supervisi terpusat pada kebutuhan dan aspirasi guru dan tetap berada di ruang lingkup tugas-tugas pembelajaran; dan

10. Prosedur pelaksanaan berupa siklus mulai dari tahap perencanaan, pelaksanaan dan pengamatan, dan siklus balikan.

Selanjutnya dikatakannya ciri-ciri supervisi klinis adalah:

1. Bimbingan supervisor pengajaran kepada guru bersifat hubungan pembantuan, bukan hubungsn perintah atau instruksi;

2. Kesepakatan antara guru dan supervisor dan tentang apa yang dikaji dan jenis ketrampilan ynng psling penting merupakan hasil diskusi bersama;

3. Instrumen supervisi klinis dikembangkan dan disepakati bersama antara guru dengan supervisor;

4. Guru melakukan persiapan dengan mengidentifikasi aspek kelemahankelemahannya yang dipandang perlu diperbaiki;

5. Pelaksanaan supervisi klinis selayaknya teknik observasi kelas;
6. Umpan balik atau balikan diberikan dengan segera dan bersifat obyektif;

7. Guru hendaknya dapat menganalisis penampilannya;

8. Supervisor lebih banyak bertanya dan mendengarkan dari pada memerintah atau mengarahkan guru;

9. Supervisor dan guru berada atau menciptakan kondisi dalam keadaan atau suasana akrab dan terbuka; dan

10. Supervisor dapat digunaka untuk membentuk atau peningkatan dan perbaikan kertampilan pembelajaran.

Tujuan supervisi klinis adalah:

1. Menjaga konsistensi motivasi dan kinerja dalam melaksanakan proses pembelajaran;

2. Mendorong keterbukaan guru kepada supervisor mengenai kelemahannya sendiri dalam melaksanakan pembelajaran;

3. Menciptakan kondisi agar guru terus menjaga dan meningkatkan mutu praktik profosional sesuai dengan standar kompetensi dan kode etik yang telah ditetapkan dan disepakati;

4. Menciptakan kesadaran guru tentang tanggung jawabnya terhadap pelaksanaan pembelajaran yang berkualitas, baik proses maupun hasilnya;

5. Membantu guru untuk senantisa memperbaki dan meningkatkan kualitas proses pembelajaran dengan jalan meningkatkan penguasan ilmu pengetahuan, teknologi, wawasan umum, dan 
keterampilan khusus yang diperlukan dalam proses pembelajaran.

6. Membantu guru untuk mengidentifikasi dan menganalisis masalah yang ditemukan dalam proses pembelajaran, baik di dalam maupun di luar kelas.

7. Membantu guru untuk dapat menemukan cara pemecahan masalah yang ditemukan dalam proses pembelajaran, sehingga benar-benar memberikan nilai tambah bag siswa dan masyarakat.

8. Membantu guru untuk mengembangkan sikap positif terhadap profesi dalam mengembangkan diri secara individual maupun kelompok, dengan cara yang dilembagakan atau inisitif sendiri.

Prosedur pelaksnaan supervisi klinis menurut Ahmad Sudrajat mengemukakan pelaksanaan supervisi klinis berlangsung dalam suatu siklus yang terdiri dari 3 tahap:

1. Tahap perencanaan awal.

Pada tahap ini beberapa hal yang harus diperhatikan : 1) menciptakan suasana yang intim dan terbuka, 2) mengkaji rencana pelajaranyang meliputi tujuan, metode, waktu, media, evaluasi hasil belajar, dll yang terkait dengan pembelajaran, 3) menentukan focus observasi, 4) menentukan alat bantu (instrument) observasi, dan 5) menentukan teknik pelaksanaan observsi.

2. Tahap pelaksanaan observasi

Pada tahap ini beberapa hal yang harus diperhatikan: 1) member penguatan, 2) mengulas kembali tujuan pembelajaran, 3) mengulas kembali hal-hal yang telah disepakati bersama, 4) mengkaji data hasil pengamatan dan tidak bersifat menyalahkan, 5) data hasil pengamatan tidak disebarluaskan, 6) penyimpulan, 7) hindari saran secara langsung, 8) merumuskan kembali kesepakatankesepakatan sebagai tindak lanjut proses perbaikan dengan kata lain prosedur penyelenggaraan supervisi klinis berlangsung dalam suatu proses berkelanjuta.

Menurut Acheson dan Gall teknikteknik dasar dalam pelaksanaan supervisi klinis meliputi tiga tahap:

- Tahap pertama, Pertemuan Perencanaan:

1. Identifikasi keprihatinan guru/calon tentang pembelajaran

2. Terjemahahkan keprihatinan ini ke dalam perilaku yang dapat diamati

3. Identifikasi prosedur untuk perbaiki pembelajaran

4. Bantu guru/calon dalam menyiapkan tujuan perbaikan dirinya

5. Siapkan waktu untuk observasi kelas

6. Pilih instrument observasi dan perilaku yang akan direkam

7. Klarifikasi konteks pembelajaran yang datanya akan direkam

- Tahap kedua, Observasi kelas: Selective Verbatin

1. Pertanyaan guru 
2. Balikan guru

3. Pernyataan dan pengarahan guru

Seating chart ibservational record:

1. Pada tugasnya

2. Urutan verbal

3. Pola gerakan

Wide Lens Technique:

1. Rekaman anekdot

2. Rekaman video dan audio

Check list:

1. Kuesioner imajinasi guru

2. Survey observasi siswa

3. Persepsi guru tentang gaya guru

4. Pembelajaran dengan cara Tanya jawab

5. Pembelajaran dengan cara ceramah

6. Pengkodean sesuai urutan waktu

- Tahap ketiga, Perteuan balikan:

1. Balikan kepada guru menggunakan data observasi yang objektif

2. Dapatkan kesimpulan, opini dan perasaan

3. Dorong guru pertimbangkan alternative tujuan pelajaran, metode-metode dan alasan-alasan.

4. Siapkan pelauan bagi guru untuk praktek dan komparasi

Gaya pertemuan: direct dan Indirect

1. Banyak mendengar, sedikit berbicara

2. Cermati, rangkum, dan gunakan apa yang dikatkan guru/calon

3. Kemukakan pertanyaan untuk klarifikasi

4. Beri penghargaan khusus penampilan dan perkembangan guru
5. Cegah member saran langsung

6. Siapkan dukungan verbal

7. Pelajari dan manfaatkan apa yang dirasakan seseorang.

Menurut Danim Teknik Supervisi klinis meliputi, teknik komunikasi ada 3 tinjauan untuk memahami konsep dasar komunikasi antara supervisor dengan guru yang disupervisi:

1. Komunikasi dipandang sebagai proses penyampaian informasi. Keberhasilan proses komunikasi antara supervisor dengan guru terletak pada penguasaan materi atau fakta dan pengaturan caracara penyampaiannya.

2. Komunikasi itu suatu proses penyampaian gagasan-gagasan dari supervisor kepada guru.

3. Komunikasi dipandang sebgai suatu proses mencipatakn arti, ide, gagasan atau konsep. Keberartian pesain itu sendiri. Tugas supervisor hanyalah menyampaikan idea tau informasi, beban pemahaman terhadap apa yang disampaikan ada pada guru yng disupervisi.

Komunikasi verbal: penggunaan kata-kata dalam menyampaikan pikiran, perasaan, dan informasi. Adalah hal yang sangat menguntungkan bila supervisor dapat menyediakan informasi tertulis mengenai cara menegakkan diagnose dan rekomendasi perbaikan bagi guru yang dibina.

Komunikasi non verbal: isyarat yang berlangsung secara sadar atau tidak sadar berupa tingkah laku yang menyatakan 
pikiran, perasaaan, atau petunjuk, yang dapat berguna dalam menunjukan emosi, sikap, membentuk dan mempertahankan hubungan social dan mendukung komunikasi verbal. Sikap non verbal yang menunjukan adanya perhatian dan kepedulian terhadap guru antara lain adalah: nada bicara, sikap, perhatian, senyuman, mendengarkan dengan seksama, posisi duduk antara supervisor pembelajarandan guru pada ketinggian yang sama.

Pendekatan GATHER:

Greet (Salam): Berikan salam dalam sikap bersahabat pada guru ketika berjumpa. Buatlah guru merasa nyaman jangan menanyakan hal-hal yang sederhanan.

Ask (Tanya): apa dan bagaimana seorang supervisor klinis dapat membantu guru. Bertanyalah mengenai masalah guru, gunakan nada suara yang mengisyaratkan kepedulian, perhatian, dan keakraban terhadap mereka.

Tell (tanggapan): berikan tanggapan dan respon terhadap kebutuhan guru

Help (bantu): bantulah guru dalam membuat keputusannya sendiri.

Explain (jelaskan) : Apa yang benar-benar perlu dijelaskan

Return (kembali): ingatkan guru dengan memberikan pesan-pesan tertentu yang penting.

Dengan memperhatikan uraian di atas, maka dapat ditarik kesimpulan bahwa supervisi klinis adalah suatu bantuan atau bimbingan yang professional oleh supervisor kepada guru/calon guru berdasarkan kebutuhan guru/calon guru melalui siklus yang sistematis atau tahapan mulai dari tahapan awal/perencanaan, tahap observasi dan tahapan balikan atau dapat dikatakan sebagai tahap pra observasi, observasi dan post observasi untuk perbaikan pembelajaran termasuk keterampilan dan sikap professional guru yang bersangkutan. Pengawas sekolah dan kepala sekolah sama-sama mengemban kompetensi supervisi. Peraturan mendiknas no. 12 tahun 2007 tentang standar pengawas sekolah dan madrasah mengemban dua diantara enam kompetensi yaitu supervisi akademik dan supervisi manajerial. Sedangkan peraturan mendiknas no. 13 tahun 2007 tentang standar kepala sekolah mengemban tuga satu dantara lima kompetensi kepala sekolah adalah kompetensi supervisi. Oleh kare itu dengan dasar inilah maka pelatihan tentang supervisi khususnya supervisi klinis bagi pengawas dan kepala sekolah merupakan suatu hal yang sangat dibutuhkan.

\section{METODE PELAKSANAAN}

\section{Khalayak Sasaran}

Khalayak sasaran kegiatan pengabdian kepada masyarakat ini adalah para pengawas dan kepala sekolah dasar di wilayah Kecamatan Dimembe Kabupaten Minahasal Utara. Jumlah peserta sebanyak 12 orang terdiri atas 2 orang pengawas, 10 
kepala sekolah, di Kecamatan Dimembe Kabupaten Minahasa Utara.

\section{Bentuk Kegiatan dan Waktu Pelaksanaan}

Bentuk kegiatan yang dilakukan yaitu: penyuluhan dan pelatihan. Waktu pelaksanaan:

1. Pertemuan I, awal bulan Mei 2016, mengadakan pertemuan dengan Kepala Dinas Pendidikan dan Kebudayaan Kabupaten Minahasa Utara membicarakan pelaksanaan pelatihan.

2. Pertemuan II, Minggu II bulan Mei 2016, mengadakan pertemuan dengan Kepala Bidang Pendidkan Dasar Dinas Pendidikan Kabupaten Minahasa Utara, mendata para pengawas dan kepala sekolah se kecamatan amuran dan membicarakan tentang pelaksanaan pelatihan.

3. Pertemuan III, Minggu III bulan Mei 2016, pelaksanaan pelatihan:

- Memberikan penjelasan maksud dan tujuan pelatihan

- Menyampaikan materi pelatihan

- Penutupan

\section{HASIL DAN PEMBAHASAN}

- Kegitan ini sangat membantu para pengawas dan kepala sekola dalam memberikan pemahaman, pengetahuan dan pengalaman tentang keterampilan teknik supervisi klinis. Mereka sangat berterima kasih atas kegiatan ini karena supervisi klinis merupakan hal yang sangat dibutuhkan para pengawas sekolah teristimewa bagi para kepala sekolah dan pengawas sekolah dasar. Semua peserta dengan antusias mengakui bahwa materi ini sangat bermanfaat untuk menambah pengetahuan dan pemahaman serta bagaimana pelaksanaan yang sesungguhnya dari supervisi klinis itu. Sebagai pengawas professional maupun kepala sekolah sebagai guru professional sama-sama mengemban tugas sebagai supervisor. Pelaksanaan teknik supervisi klinis sangat membantu tugas mereka khususnya dalam membantu, membimbing para guru dalam memperbaiki dan meningkatkan proses pembelajaran disekolah.

- Berpengaruh terhadap penampilan pelaksanaan tugas sebagai pengwas sekolah maupun kepala sekolah sehingga dalam melaksanakan tugas supervisi akan menggunakan cara-cara supervisi klinis yang mereka telah dapatkan dalam pelatihan. Dengan harapan pula akan berdampak pada suasana kelas dalam arti ada perubahandan peningkatan dalam interaksi pembelajaran oleh guru.

\section{KESIMPULAN}

\section{Kesimpulan}

Berdasarkan hasil penelitian dan diskusi dengan peserta ternyata materi supervisi klinis ini merupakan materi yang sangat mereka aharapkan dan sangat 
dirasakan manfaatnya terutama dalam pelaksanaan tugas mereka sebagai pengawas sekolah dalam rangka membantu guru ketika mereka menghadapi permasalahan dalam proses pembelajaran di kelas. Menurut peserta bahwa materi ini harus disosialisasikan dan dipraktekan oleh semua pengawas sekolah termasuk kepalas sekolah bukan hanya di kecamatan amurang tetapi diseluruh kabupaten Minahasa selatan bahkan diprovinsi Sulawesi utara

\section{Saran}

- Diharapkan kepada Dinas pendidikan Pemuda dan olahraga kecamatan, kabupatenkota maupun propinsi untuk menindak lanjuti pelatihan ini baik berupa pelatihan lanjutan maupun pelatihan bagi semua pengawas maupun kepala sekolah bahkan bagi guru-guru, sehingga baik yang mengawas ataupun yang diawasi telah memahami betapa pentingnya supervisi klinis.

- Kepada pihak dinas pendidikan bilamana akan melaksanakan pelatihan ini dapat berkoordinasi dengan pihak perguruan tinggi dalam hal ini Universitas Negeri Manado Fakultas Ilmu Pendidikan atau Jurusan/prodi yang terkait terutama berkaitan dengan narasumber yang berkompeten untuk bidan ini.

- Kepada lembaga Pengabdian pada masyarakan Universitas Negeri Manado kiranya dapat memprogramkan pelatihan serupa bagi para pengawas pendidikan, kepala sekolh sebagai pengawas di sekolah untuk berbagagi jeni dan jenjang pendidikan dapat melaksanakan supervisi klinis.

\section{KEPUSTAKAAN}

Danim Sudarwan, Khairil. H., Profesi Kependidikan, 2011, Alfabeta, Bandung.

Griffin W., Rickey, Moorhead, Gregory, Organizasional Behavior, 1986, Houghton Mifflin Company, Boston.

Sargiovanni, Th.J., Starrat J.R., Supervision Human Perspective, 1983, thir edition, Mc-graw-Hill Book company, New York

Peraturan mendiknas no.12 tahun 2007 tentang standar pengawas sekolah dan madrasah

Peraturan mendiknas no. 13 tahun 2007 tentang standar kepala sekolah

Undang-undang RI nomor 20 tahun 2003, Sistem pendidikan Nasional.

Jurnal Vol. 3 Tahun 2013 Luh Amani, Nyoman Dantes, Wayan Lasmawan "Implementasi supervisi klinis dalam rangka meningkatkan kemampuan guru mengelola proses pembelajaran pada guru sd se-gugus vii kecamatan sawan" diunduh pada tanggal 20 Juni 2016

Undang-undang RI nomor 14 tahun 2005, Guru dan Dosen

PP RI No. 19 tahun 2005: Standar Nasional Pendidikan dirubah dalam PP rI N0.32 Tahun 2013

PP RI No. 74 Tahun 2008: Guru

Permendiknas No. 16 Tahun 2007: Standar Kualifikasi Akademik dan Kompetensi guru 
Jurnal ABDIMAS, Vol. 9, No. 1, Juni 2016 ISSN: 1979-0953 